
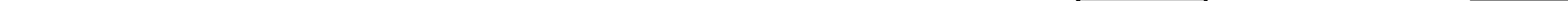


\title{
HEIDEGGER Y LA PREGUNTA POR EL SENTIDO DEL SER
}

\section{HEIDEGGER AND THE QUESTION ABOUT SENSE OF BEING}

\author{
Alejandro EsCUdero PÉREZ ${ }^{1}$ \\ $U N E D$
}

RESUMEN: La contribución más duradera de Heidegger a la filosofía de nuestra época consiste en la defensa del cometido "ontológico» de la filosofía. En su amplio itinerario planteó la pregunta por el ser de tres maneras: como pregunta por el sentido del ser, la verdad del ser y el lugar del ser. En este artículo examinaremos críticamente su primera formulación: la que desembocó en una de las obras más influyentes del siglo XX, Ser y tiempo.

Palabras ClaVE: ontología, analítica del Dasein, sentido del ser, tiempo, idealismo.

ABSTRACT: Heidegger's most lasting contribution to philosophy of present day consists of vindication for «ontological» task of philosophy. All through his intellectual run he posed the question about Being in three different ways: as a question for the sense of being, for the truth of being an for the place of being. In this report we'll analyse in a critical way his first explanation: that resulted in one of most influential books in the twentieth century, "Being and Time».

KEYWORDS: ontology, analytics of Dasein, sense of being, time, idealism.

${ }^{1}$ Este artículo ha sido elaborado dentro del Proyecto de Investigación FFI2009-11921, denominado «Interpretación y verdad en la hermenéutica fenomenológica», dirigido por Ramón Rodríguez García. 


\section{Introducción}

La mejor contribución de Martin Heidegger a la filosofía contemporánea se cifra, nos parece, en el tesón y la insistencia con la que ha sostenido que la pregunta filosófica central es la pregunta por el ser. Si esto fuese en verdad así —como nosotros, con él, afirmamos - la filosofía sólo realizaría su más alta y noble posibilidad cuando se plantea y desarrolla como «ontología». A su vez, y es algo que merece consideración y examen, no se puede pasar por alto que Heidegger formuló la investigación ontológica, en su larga y prolífica trayectoria, de tres maneras diferentes: como interrogación por el «sentido del ser», por la «verdad del ser» y por el «lugar del ser» ${ }^{2}$.

El objetivo de este artículo es plantear una crítica del primer programa filosófico de Heidegger, el que propuso en los años veinte del siglo pasado. Así pues aunque aceptamos que la principal pregunta filosófica es la "pregunta por el ser» sin embargo entendemos que es profundamente incorrecto plantearla y desarrollarla como indagación dirigida hacia el «sentido del ser». Cuando la filosofía se empeña en buscar una respuesta a esta pregunta se ve avocada, inevitablemente, a un callejón sin salida: se encalla, naufraga. La inconclusión de Ser y tiempo es una prueba de que el propio Heidegger - convencido poco a poco por la fuerza de los fenómenos- cayó en la cuenta de que el edificio que con tanto esfuerzo hacía alzado estaba lleno de grietas y era inhabitable. Nuestra meta, en definitiva, está en explicar, lo mejor que sepamos, por qué la pregunta por el sentido del ser resulta insostenible, es desacertada y reclama ser reformulada.

Afirmar por nuestro lado — siguiendo, en parte al propio Heidegger, aunque también por nuestra cuenta y riesgo- que la pregunta por el sentido del ser es una mala pregunta - y una mala pregunta, un problema erróneamente planteado, no puede tener una buena respuesta - no evita reconocer y poner de relieve que el «primer Heidegger» hizo hallazgos filosóficos de primera magnitud —hallazgos que merecidamente reclaman ser retomados y asumidos con todas sus consecuencias-. Mencionaremos aquí, por ejemplo, los seis siguientes: el ser se da en una comprensión; el ser es, a la vez, principio determinante de los entes y diferen-

2 Véase Martin Heidegger (1995), Seminario de Le Thor (1969), Alción, pp. 39 y ss. (el texto original está recogido en el volumen $n .^{\circ} 15$ de las Obras Completas, editorial Vittorio Klostermann). 
te de todos ellos; el ser-en-el-mundo (y no un sujeto opuesto y enfrentado a un objeto) es un fenómeno primario; la verdad no es sólo «adecuación» ni reside exclusivamente en los juicios o enunciados, es, también, «apertura y descubrimiento»; el tiempo no es únicamente «sucesión»; el espacio no es solamente «extensión» (o, dicho de otro modo, espacio y tiempo son algo más que un continente vacío de carácter continuo, homogéneo e ilimitado). Estos y otros importantes hallazgos, de todos modos, no pudieron, sin embargo, desarrollarse en su irrupción primera según sus mejores posibilidades por el efecto que sobre ellos operaban unas coordenadas filosóficas - las inherentes a la pregunta por el sentido del ser- que terminaban malográndolos.

En un primer momento explicaremos en qué consiste la pregunta por el sentido del ser, y, a continuación, por qué, a nuestro juicio, nos parece una cuestión fallida, una pregunta y una investigación que, en definitiva, requiere ser planteada de otra manera.

\section{La pregunta por el sentido del ser}

En el $₫ 1$ de Ser y tiempo Heidegger afirma que es menester emprender una «repetición» de la "pregunta por el ser» ${ }^{3}$; una pregunta que tiene su partida de nacimiento en Grecia, es decir, en el lugar en el que surgió - en un determinado momento- un peculiar saber denominado desde entonces «filosofía». Este «hecho» (este singular acaecer griego de la filosofía) no basta sin embargo para justificar que la pregunta por el ser es la pregunta que tiene que ser retomada y relazanda. Así lo decía Heidegger en 1925: «Si la cuestión fundamental acerca del ser resulta ser una cuestión que nos permite revivificar la filosofía científica clásica, la de los griegos, no por eso se puede tomar este hecho histórico, digamos, como si se tratara de una prueba de autoridad que demuestra lo correcto de la cuestión. Antes bien no es más que un indicio de que esa cuestión se halla

3 En el libro que Heidegger publicó en 1929 explicaba así el significado de «repetición» (como modo de encarar el arranque de un preguntar filosófico): «Entendemos por repetición de un problema fundamental el descubrimiento de sus posibilidades originarias, hasta entonces ocultas. El desarrollo de éstas lo transforma de tal suerte que por ello mismo logra conservar su contenido problemático. Conservar un problema significa librar y salvaguardar aquellas fuerzas internas que lo posibilitan como problema según el fundamento de su esencia», Heidegger (1986), Kant y el problema de la metafísica, Méjico, FCE, p. 173. 
a la vista en el curso de las indagaciones. ¿Por qué la filosofía ha de plantear justamente esa cuestión acerca del ser? ¿Qué es, entonces, la filosofía, para que tenga que hacerlo?» ${ }^{4}$. Deben, pues, ofrecerse, a fin de sostener esta tesis, argumentos complementarios.

Que la "pregunta por el ser», inicialmente formulada por los griegos, va a ser «repetida» indica además, como antes quedó sugerido, que se la va a transformar de alguna manera: la "repetición», tal como Heidegger la entiende, no es una pura reiteración que deja intacto lo repetido. Así en su primer programa filosófico no se plantea simplemente la "pregunta por el ser», sino que se introduce en ella un matiz decisivo, un giro que lo cambia todo: se formula la pregunta por el «sentido del ser». Ya en el exergo al libro de 1927 leemos: «La elaboración concreta de la pregunta por el sentido del «ser» es el propósito del presente tratado»"

En el $₫ 1$ de Ser y tiempo Heidegger discute tres argumentos que han sido propuestos en diversas ocasiones con el fin de sostener que la pregunta por el ser es innecesaria y, en el fondo, superflua. Más que lo que Heidegger contraargumenta frente a ellos nos interesa ahora destacar tres tesis positivas que se desprenden de lo que este parágrafo expone:

1. Debe encararse la cuestión de la «unidad del ser» (unidad de una multiplicidad aborda, finalmente, como «unidad de sentido» — por este motivo se formula el problema principal de la filosofía en forma de una investigación orientada hacia el sentido del ser en general-).

2. Se lo conciba como se lo conciba al final de la indagación en todo caso el «ser» no es un ente (es decir, debe suponerse la diferencia del ser respecto a todo lo óntico).

${ }^{4}$ Heidegger (2006), Prolegómenos para una historia del concepto de tiempo, Madrid, Alianza, p. 172. En el mismo sentido un poco antes, en la página 170, se dice: «Resulta así que la fenomenología, radicalizada en su posibilidad más propia, no es sino el cuestionar redivivo de Platón y Aristóteles: la repetición, la recuperación del inicio de nuestra filosofía cientifica. Ahora bien, de este modo, ¿no se renuncia a toda prevención crítica que se exigía frente a la tradición? Al fin y al cabo, la cuestión acerca del ser, justamente por lo venerable de su origen, que remite hasta Parménides, ¿no es también un prejuicio? ¿Es que acaso, sólo porque los griegos así se lo plantearon, hemos de cuestionarnos lo mismo?».

5 Heidegger (2003), Ser y tiempo, Madrid, Trotta, p. 23. 
3. Ya siempre $-y$ con independencia de que planteemos o dejemos de plantear cuestión filosófica alguna- estamos en una "comprensión del ser» (la cual rige de antemano en cualquier aprehensión del ente como esto o como aquello «ser», pues, es un término que denomina al «principio determinante») ${ }^{6}$. Otra manera de decir lo mismo: el ser «se da» en una comprensión o a una comprensión 7 .

Vayamos, ahora, al $\$ 2$ de Ser y tiempo. De su lectura de conjunto - y enseguida entraremos en detalles- cabe establecer tres conclusiones. En primer lugar —e insistimos con ello en un punto crucial — que eso a lo que se llama «ser» por un lado es lo que determina al ente como ente (en su estar siendo tal o cual) y, por otro lado, a la vez, no es él mismo ente alguno (no es, pues, por ejemplo, un «ente supremo»). En segundo lugar se especifica que, sea lo que sea, el «sentido» es algo situado «más allá» del ser ${ }^{8}$. En tercer lugar se afirma que la pregunta filosófica indaga únicamente en torno al «ser del ente»" —algo de lo que se concluye que la «ontología» tiene que tener, necesariamente, un «fundamento óntico» ${ }^{10}$-.

${ }^{6}$ «Lo que determina [bestimmt] lo ente en cuanto ente es su ser», Heidegger, Prolegómenos para una historia del concepto de tiempo, op. cit., p. 181.

7 Bien es cierto que, siempre a nuestro juicio, el "primer Heidegger» no supo muy bien —como iremos viendo- qué hacer con ese «se da», con ese «darse del ser» en la comprensión. Que el ser «se da» una y otra vez y de vez en vez aconteciendo es una tesis del «segundo Heidegger» (no del «primero» que termina diciendo que el «ser» es lo que resulta «proyectado» por una proyección del Dasein, etc. — véase lo que agudamente explica al respecto Ramón Rodríguez en la p. 121 de Heidegger y la crisis de la época moderna, ed. Síntesis, 2006-).

${ }^{8}$ Felipe Martínez Marzoa ve así el asunto: «La manera en que hemos mencionado «el sentido del ser» parece señalar en cierto modo hacia más allá del «ser», esto es: a un problema que sería más originario que el mero "problema del ser»... lo que parece ocurrir es que se retrocede un paso a partir del asunto «ser», y que precisamente la fórmula «el sentido del ser» designa eso hacia lo cual se retrocede»; Martínez Marzoa (1985) El sentido y lo no-pensado, Univ. de Murcia, pp. 11-12. Heidegger conecta en (2000), Los problemas fundamentales de la fenomenología, Madrid, Trotta, pp. 339 y ss., este "más allá del ser» —implícito en la noción de «sentido»— con la temática platónica del «epékeina» atribuido a la Idea del Bien (la cual estaría «más allá» de lo eidético mismo).

9 Decimos «únicamente» para subrayar por nuestra parte un motivo crítico. En su punto álgido - y el «segundo Heidegger» asentiría a esto— la pregunta ontológica se dirige al «ser en cuanto ser», es decir, se orienta hacia el «ser del ente» sin partir del ente (sin tomar algo óntico como «modelo» de lo ontológico, etc.).

10 Si se toma plenamente en serio la "diferencia ontológica» esta idea es en todo punto inaceptable. Es esta una de las principales razones que permiten concluir, como más adelante expondremos, lo desacertado de la pregunta por el «sentido del ser». 
Lo primero que toca es plantear la pregunta filosófica: elaborarla. Sin esto la investigación carece de dirección y pierde el norte. ¿Cómo conseguirlo de tal manera que se organice una indagación precisa? Inicialmente es menester tornar explícitos los elementos inherentes al preguntar. Heidegger hace esto en el $\$ 2$ de Ser y tiempo. Aquí nos dice: «Todo preguntar implica, en cuanto preguntar por ... algo puesto en cuestión [sein Gefragtes]. Todo preguntar por ... es de alguna manera un interrogar a ... Al preguntar le pertenece, además de lo puesto en cuestión, un interrogado [en Befragtes]. En la pregunta investigadora, es decir específicamente teorética, lo puesto en cuestión debe ser determinado y llevado a concepto. En lo puesto en cuestión tenemos entonces, como aquello a lo que propiamente se tiende, lo preguntado [das Erfragte], aquello donde el preguntar llega a su meta». Distingue Heidegger, por lo tanto, entre: lo que se pregunta o lo preguntado (Erfragte) —eso que constituye el objetivo del conjunto de la indagación-; lo que se pregunta o por lo que se pregunta (Gefragte); eso a lo que se pregunta. Partiendo de aquí debe darse un paso más: «La cuestión está verdaderamente planteada cuando el preguntar se ha elaborado de la manera correcta en estos sus tres elementos esenciales. En consecuencia, hay que exponer de modo más preciso la cuestión en esos tres aspectos» (Prolegómenos para una historia del concepto de tiempo, op. cit., p. 182). Un requerimiento al que responde así Heidegger: «1. Lo que se pregunta (Erfragte): el sentido del ser. 2. Aquello por lo que se pregunta (Gefragte): el ser de lo ente. 3. Aquello a lo que se pregunta (Befragte): lo ente mismo» (Ibíd.., p. 182). En primer lugar — según el orden de la investigación — la clave se encuentra en el tercer elemento, pues, dentro de la enorme y variopinta multiplicidad de lo óntico, algo debe destacarse con el fin de formularle la pregunta filosófica: «¿En cuál ente debe leerse el sentido del ser, desde cuál ente deberá arrancar la apertura del ser? ¿Es indiferente el punto de partida o tiene algún determinado ente una primacía en la elaboración de la pregunta por el ser? ¿Cuál es este ente ejemplar y en qué sentido goza de una primacía?» (Ser y tiempo, $\$ 2$, op. cit., p. 30). Pregunta crucial y, pues, respuesta decisiva. $Y$ ¿qué responde Heidegger? Nada menos que —en un giro que cabe calificar de «moderno»— esto: el ente «señalado» — «ejemplar», "privilegiado»— soy yo o somos nosotros mismos. Se aproxima así a la "filosofía del sujeto» que impera en la era moderna del mundo (recuérdese lo que Kant sostenía: la pregunta primordial de la filosofía, esa a la que deben remitirse todas las demás, es la que reza "¿Qué es el Hombre?»). Una proximidad, sin embargo, distante, nada ingenua. La respuesta de Heidegger puede discutirse, pero no por precipitada o por automática. Para percatarse de 
esto basta reparar en que cuando Heidegger adopta un término como «Dasein» para referirse al ente que somos nosotros o que soy yo lo hace con el fin de evitar otros — más «claros y obvios» si se quiere, pero también más lastrados (nociones como "conciencia», «alma», «espíritu», «mente», o la expresión «animal racional» $)^{11}$ —. Tiene, de todos modos, que preguntarse si el primer programa filosófico de Heidegger es o no es — con los matices que sea- una "filosofía del sujeto» (del «hombre» como fundamento del mundo). Pero, por ahora, nos concentraremos sólo en exponer los dos primeros argumentos que aduce Heidegger para justificar esta comprometida - y muy discutible, a nuestro juicio- respuesta. Debe preguntarse al Dasein: porque es el ente que pregunta (y pregunta por el ser y su sentido) ${ }^{12}$; porque es el ente que comprende el $\operatorname{ser}^{13}$. Vaya por delante que ninguno de estos dos argumentos nos parece convincente ${ }^{14}$, pero el hecho es que son los que Heidegger tiene en cuenta $-y$ lo que sirvieron de trampolín para armar un tratado tan sólido y riguroso como Ser y tiempo-. ¿Qué se concluye de todo esto? Leemos en el $\$ 2$ del libro de 1927: «El planteamiento explícito y transparente de la pregunta por el sentido del ser [en general] exige la previa y adecuada exposición de un ente (el Dasein) en lo que respecta a su ser [y su sentido]» (op. cit., p. 30).

${ }^{11}$ La pregunta kantiana, por otra parte, se responde delimitando una «esencia», la «esencia del hombre» (que Kant define como «Sujeto racional» en el que todo encuentra su fundamento); sin embargo, y no es esta una diferencia menor, el «Dasein» es un ente sin «esencia», véase Heidegger (2003), Ser y tiempo, op. cit., $\$ 2$, p. 35).

12 «Elaborar el planteamiento de la cuestión acerca del sentido del ser quiere decir: poner al descubierto el preguntar en cuanto ente, es decir, poner de manifiesto al propio Dasein»; «Elaborar el planteamiento de la cuestión es experimentar y explicar antes de nada el propio ente que pregunta —el Dasein que nosotros mismos somos—", Prolegómenos para una historia del concepto de tiempo, op. cit., pp. 186 y 188.

${ }_{13}$ No se trata aquí, únicamente, de que en efecto una y otra vez — rigiendo todo trato con el ente y, a la vez, toda comparecencia suya — «comprendamos ser» — algo, nos parece, acertadoA esto añade Heidegger algo más: «La comprensión del ser tiene ella misma el modo de ser del Dasein humano", Los problemas fundamentales de la fenomenología, op. cit., p. 41 (¿y si esto último fuese falso? Entonces no cabría atribuir al Dasein una completa primacía en el seno de la investigación ontológica).

${ }^{14}$ En primer lugar el que sea yo (o el que seamos nosotros) el que pregunta no implica que la pregunta tenga que referirse a mí mismo; por otro lado que nos sea «inherente» la «comprensión del ser» (expresión, por cierto, afectada por una dañina ambigüedad de la que más adelante hablaremos) no significa en modo alguno que sea «nuestra» (en la acepción enfática del término). 
Antes de adentrarnos en los $\$ \$ 4$ 4-5 de Ser y tiempo —en los que se precisan las razones de la primacía del Dasein en el seno de la pregunta ontológica- nos detendremos en el $\$ 3$. A partir de él vamos a destacar algo en lo que no suelen insistir como merece muchas de las exposiciones de la obra de Heidegger. La «totalidad del ente» — se nos explica aquí — está dividida y agrupada según regiones categoriales ${ }^{15}$. Cabe, así, desarrollar una serie de "ontologías regionales» en las que se pregunta por el «ser del ente» de cada una de las regiones que puedan resultar legítimamente diferenciadas; una "ontología regional», en definitiva, pretende tornar explícita la "constitución del ser» (Seinsverfassung) el ente categorialmente regionalizado ${ }^{16}$. Ya expresamente, en un curso de 1925 (Prolegómenos para una historia del concepto de tiempo, $\$ 2$ ), se refería Heidegger a «la pregunta por el ser del ente y sus posibles regiones». ¿Qué significa esto? Ante todo que elaborar las ontologías regionales forma parte del programa filosófico que Heidegger pretendía sacar adelante. Por otro lado, y aunque nunca fue suficientemente preciso en este punto, Heidegger distinguía cuatro regiones categoriales $-\mathrm{y}$, así, cuatro posibles ontologías regionales - : la del ente utilizable, el ente subsistente, el ente vivo y el ente ideal ${ }^{17}$.

Si preguntamos, ¿por qué no insistió con la debida claridad en esta importante vertiente de la pregunta por el ser? Principalmente, nos parece, porque Heidegger quería destacar y resaltar enérgicamente que la pregunta por el «sentido del ser en general» es una cuestión más originaria que la que formulan una por una las diferentes ontologías regionales. Es más: sólo desde una respuesta a aquella puede propiamente buscarse una respuesta a éstas ${ }^{18}$. Así lo expresa el siguiente texto: «Pero semejante cuestionamiento — que es ontología, en su acep-

15 Tal vez esto no sea así y, en cambio, la «totalidad del ente» esté dividida no según "géneros ónticos» (o "clases de entes») sino conforme a «ámbitos del saber» (la ciencia o el arte, por ejemplo). No es este el sitio, sin embargo, de abordar tan crucial —y difícil— asunto.

${ }^{16}$ Esta "constitución del ser» incluye tres ingredientes: la "esencia», la "existencia» y la "verdad» del ente. Sobre este punto véase, por ejemplo, Heidegger, Kant y el problema de la metafísica, $\$ 40 \mathrm{y} \$ 41$.

17 En su libro La segunda mitad de Ser y tiempo, F.-W. von Herrmann, ed. Trotta, 1997, alude a esta división en las páginas 45 y 59.

18 «El significado más propio de la respuesta [a la pregunta por el sentido del ser en general] consiste prescribir a la investigación ontológica concreta que dé comienzo a la interrogación investigante dentro del horizonte que habrá sido puesto al descubierto. La respuesta no da más que esto", Ser y tiempo, $\$ 5$, p. 43 . 
ción más amplia, y con independencia de corrientes y tendencias ontológicasnecesita, a su vez, de un hilo conductor. El preguntar ontológico [regional] es ciertamente más originario que el preguntar óntico de las ciencias positivas. Pero él mismo sería ingenuo y opaco si sus investigaciones del ser del ente dejaran sin examinar el sentido del ser en general. Y precisamente la tarea ontológica de una genealogía no deductivamente constructiva de las diferentes maneras posibles de ser, necesita de un acuerdo previo sobre lo «que propiamente queremos decir con esta expresión "ser". La pregunta por el ser apunta, por consiguiente, a definir las condiciones a priori de la posibilidad no sólo de las ciencias que investigan el ente en cuanto tal o cual, y que por ende se mueven ya siempre en una comprensión del ser, sino que ella apunta también a definir la condición de posibilidad de las ontologías mismas que anteceden a las ciencias ónticas y las fundan. Toda ontología, por rico y sólidamente articulado que sea el sistema de categorías de que dispone, es en el fondo ciega y contraria a su finalidad más propia si no ha aclarado primero suficientemente el sentido del ser y no ha entendido esta aclaración como su tarea fundamental» (Ser y tiempo, $\$ 3$, p. 34). Es decir, y en definitiva: la cuestión de la «unidad del ser» (como «unidad de sentido») es "anterior» en rango a la indagación sobre la multiplicidad de las regiones categoriales.

Vayamos, ahora sí, con la importante cuestión de la «primacía del Dasein» (en la que se juega buena parte del primer intento filosófico de Heidegger). El ente que soy yo o somos nosotros merece — presuntamente - una prioridad en el terreno de los problemas ontológicos porque — como antes señalamos- «comprende el ser». La expresión, tal como la emplea Heidegger, es ambigua (una ambigüedad que encierra, nos parece, uno de los problemas de fondo en los que encalló, finalmente, este programa filosófico). Por una lado alude a que el Dasein se comprende (le va su ser, mantiene una relación de ser consigo mismo, etc.); por otra parte se refiere a que el Dasein «comprende el ser de todo lo que es». La duda que puede plantear este enfoque es: ¿preguntamos inicialmente al Dasein porque comprende, ante todo, su propio ser $o$ porque comprende el ser de todo lo óntico? Veamos, antes de responder, como Heidegger aborda las coordenadas del tema. En el $\$ 4$ dice:

«Es propio de este ente el que con su ser y por su ser éste se encuentre abierto para él mismo. La comprensión del ser es, ella misma, una determinación de ser del Dasein» (Ser y tiempo, op. cit., p. 35). 
«La comprensión del ser propia del Dasein comporta, pues, con igual originariedad, la comprensión de algo así como un «mundo» y la comprensión del ser del ente que se hace accesible dentro del mundo» (op. cit., p. 36) ${ }^{19}$.

El asunto, así planteado, resulta aparentemente claro y la ambigüedad que hemos subrayado por nuestra parte parece que no genera problema alguno: el Dasein —el ente que soy o somos — comprende a la vez su ser $y$ el ser de todo lo óntico, sea como sea, pertenezca a una u otra de las regiones categoriales. Sin embargo con solo hurgar un poco más en el asunto empieza a verse que aquí se esconden — se camuflan - profundas dificultades ${ }^{20}$. Para mostrarlo basta, inicialmente, indicar que Heidegger sitúa en este punto (en la «y» que acabamos de escribir en cursiva) la alternativa que principalmente concierne al Dasein: la de «ser él mismo» $o$ «no serlo», la opción entre «autenticidad» $o$ «inautenticidad». El Dasein propio y auténtico es el que se comprende a sí mismo y nada más que a sí mismo ${ }^{21}$. Es esto, precisamente, lo que puede concluirse de la lectura del $₫ 5$ del tratado de 1927. En él comienza Heidegger diciendo que el Dasein carece de la transparencia e inmediatez de acceso de la que presume la autoconciencia reflexiva, esa que cree poder captarse «sin distancia» $\mathrm{y}$ «sin intermediario»: «La demostración de la primacía óntico-ontológica del Dasein podría llevarnos a pensar que este ente debe ser también lo primariamente dado desde el punto de vista óntico-ontológico, no sólo en el sentido de una «inmediata» aprehensibilidad del ente mismo, sino también en el sentido de un igualmente «inmediato» darse de su modo de ser. Sin lugar a dudas, el Dasein está no sólo ónticamente cerca, no sólo es lo más cercano — sino que incluso lo somos en cada caso nosotros mismos - Sin embargo, o precisamente por eso, el Dasein es ontológicamente lo más lejano. Ciertamente a su modo más propio de ser le es inherente tener una comprensión de este ser y moverse en todo momento en un cierto estado interpretativo respecto de su ser» (op. cit., p. 39). ¿A qué se debe esa "lejanía»? ¿Qué implica? ¿Qué consecuencias tiene? «El Dasein tiene, más bien, en virtud

19 «... al Dasein le pertenece con igual originariedad — como constitutivo de la comprensión de la existencia- una comprensión de todo ente que no tiene el modo de ser del Dasein», op. cit., p. 36.

${ }^{20}$ A nuestro juicio, y es una de las principales razones para afirmar que la pregunta por el sentido del ser es una pregunta desacertada, Heidegger no consiguió aclarar el nexo entre el «Dasein» y la «comprensión del ser». O dicho de otro modo: lo que propuso con el fin de lograr esa aclaración no puede ser sostenido. Volveremos sobre ello.

${ }^{21}$ Se verá, en su momento, qué significa, en profundidad, esa «nada». 
de un modo de ser que le es propio, la tendencia a comprender su ser desde aquel ente con el que esencial, constante e inmediatamente se relaciona en su comportamiento, vale decir, desde el «mundo». En el Dasein mismo y, por consiguiente, en su propia comprensión de ser, hay algo que más adelante se mostrará como el reflejarse ontológico de la comprensión del mundo sobre la interpretación del Dasein» (op. cit., pp. 39-40). Sucede, pues, o eso afirma Heidegger, que el Dasein se inclina inevitablemente a comprenderse desde el mundo y lo mundano, es decir: a comprenderse desde o hacia lo que no es él (de lo que él no es) con la fatal consecuencia de que así resulta expropiado de su auténtico y propio ser y sentido. Se dibuja así, a contraluz, la idea de que el Dasein es propio y auténtico cuando se mantiene en una pura comprensión de sí mismo y por sí mismo, donde "pura» significa: no contaminada —oscurecida, ensuciada - por el mundo y lo mundano. Por lo tanto, y en efecto, el Dasein no sólo comprende su ser, también comprende el «mundo», etc., pero el precio que paga por esto último es altísimo: la expropiación de su ser y sentido; la «inautenticidad» inherente —así lo cree Heidegger- al «arrojamiento en el mundo», a la «caída en el círculo de la cotidianidad». En definitiva, y aquí pretendíamos llegar, la respuesta que Heidegger da a la pregunta que antes formulamos es ésta: preguntamos — de cara a plantear y desarrollar una «ontología»— al Dasein ante todo porque se comprende a sí mismo (y, secundariamente, porque, además, comprende el ser de todo lo que es — de tal manera que por hacer esto último pierde su ser más propio, le es arrebatado su auténtico ser-).

Apuntado esto - y aparcando por ahora los problemas que hemos detectado hasta aquí- es oportuno volver a lo que Heidegger concluyó de sus argumentaciones: la necesidad de emprender una «analítica del Dasein» — necesidad debida a la prioridad que ostenta este ente en el conjunto de la problemática ontológica-. Heidegger así lo expresa: «El Dasein se ha revelado, pues, como aquello que, desde un punto de vista ontológico, debe ser interrogado con prioridad a todo otro ente» (Ser y tiempo, $\$ 4$, op. cit., p. 36) ${ }^{22}$.

Es el momento — antes de profundizar en cómo se platea y se desarrolla la «analítica del Dasein»— de ofrecer una primera explicación de qué significa —y a qué apunta— eso del «sentido del ser» (luego diremos algo respecto al tér-

22 «Una analítica del Dasein debe constituir, pues, la primera exigencia que plantea el desarrollo de la pregunta por el ser» (Ser y tiempo, $\$ 5$, p. 40). 
mino «en general» que es necesario añadir para dar una formulación completa del tema).

Heidegger $-\mathrm{y}$ es un punto fuerte de su propuesta (que merece ser mantenido)— anuda «ser» y «comprensión». Así en el $\$ 39$ de Ser y tiempo leemos: «El ente es independientemente de la experiencia, conocimiento y aprehensión por medio de los cuales queda abierto, descubierto y determinado. En cambio, el ser sólo «es» en ... eso que llamamos comprensión del ser» (op. cit., p. 206). Tenemos aquí, nos parece, un importante hallazgo de merece ser recogido, asumido, desarrollado. Ahora bien, Heidegger no sólo alude al ser y su comprensión sino que introduce — arruinando, finalmente, el asunto mismo - la cuestión del «sentido del ser». Veamos en qué términos ocurre esto.

El sentido (del ser) se sitúa, de entrada, «más allá» (y, por ello, «antes», "por encima») del ser mismo. Es decir: sea lo que sea el «sentido» es más originario, es prioritario respecto al «ser». Por ser así — si así fuese- el pensar ontológico debe estar orientado hacia un rebasar o exceder al «ser» hacia su "sentido». Pero, propiamente, ¿a qué se alude con éste? El término «sentido» se trae a colación, en primera instancia, como respuesta a una pregunta. En ésta se inquiere lo siguiente: ¿a partir de qué (desde o hacia qué) el «ser» resulta comprendido o comprensible (para y por el Dasein)? ${ }^{23}$. Pues bien: eso a partir de lo cual se comprende «ser» es precisamente el «sentido». Varios textos — cada uno de los cuales aporta un matiz en el tema- lo explican así:

"Cuando un ente intramundano ha sido descubierto por medio del ser del Dasein, es decir, cuando ha venido a comprensión, decimos que tiene sentido. Pero lo comprendido no es, en rigor, el sentido, sino el ente o, correlativamente, el ser. Sentido es aquello en lo que se mueve la comprensibilidad de algo" (Ser y tiempo, op. cit., \$32, p. 175).

«QQué significa sentido?... Sentido es aquello en que se mueve la comprensibilidad de algo ... sentido significa, pues el fondo desde el cual (woraufhin)...puede concebirse la posibilidad de que algo sea lo que es ... es decir, [es] aquello que hace posible algo»(Ser y tiempo, op. cit., $\$ 65$, p. 341).

23 "¿A partir de qué debe comprenderse el ser?» (Prolegómenos para una historia del concepto de tiempo, op. cit., p. 172); «¿Qué es lo que hace posible esta comprensión del ser en general? ¿A partir de qué, es decir, a partir de qué horizonte previamente dado comprendemos algo así como el ser» (Los problemas fundamentales de la fenomenología, op. cit., p. 41). 
«Estrictamente hablado sentido significa el fondo desde el cual se lleva a cabo el proyecto primario de la comprensión del ser» (Ser y tiempo, op. cit., $\$ 65$, p. 342$)^{24}$.

Por lo tanto, y en definitiva, «sentido» es — respecto al ser y su comprensión— lo posibilitante, lo condicionante, es decir, la "condición de posibilidad» de la comprensibilidad (Verständlichkeit) del ser. Pero lo principal, de acuerdo con nuestra perpectiva, es intentar aclarar qué consecuencias tiene este planteamiento de la pregunta ontológica. Y cabe destacar dos consecuencias - una de ellas matizable, la otra rechazable—: el ser está «inmerso» en la comprensión ${ }^{25}$; el ser es «dependiente» de la comprensión ${ }^{26}$.

Después de esto - muy problemático, a nuestro entender- la conclusión de Heidegger es nítida: «La pregunta por el sentido del ser sólo es posible si se da algo así como una comprensión del ser. Al modo de ser del ente que llamamos Dasein le pertenece la comprensión del ser. Cuanto más adecuada y originaria haya podido resultar la explicación de este ente, con tanto más seguridad el proceso ulterior de la elaboración del problema ontológico-fundamental llegará a su meta» (Ser y tiempo, op. cit., $\$ 44$, p. 221). Se justifica así la necesidad de llevar a cabo una «analítica del Dasein» bajo la idea de que gracias a ella, y en ella, se pondrá de relieve la «condición de posibilidad» de la comprensión del ser, es decir, su «sentido» ${ }^{27}$.

${ }^{24} \mathrm{Si}$ respondemos a la pregunta ¿quién lleva a cabo ese "proyecto primario» en que consiste el «sentido»? habremos dado con la clave de lo que sostiene el primer Heidegger.

25 «Y cuando preguntamos por el sentido del ser, la investigación no se torna por eso profunda, ni intenta alcanzar, a costa de cavilaciones, algo que estuviera detrás del ser, sino que pregunta por el ser mismo en tanto que inmerso en la comprensibilidad del Dasein», Ser y tiempo, op. cit., $\$ 32$, p. 175 .

26 «Ciertamente tan sólo mientras el Dasein, es decir, mientras la posibilidad óntica de comprensión del ser, es, «hay» ser ... La recién caracterizada dependencia del ser — no de los entesrespecto de la comprensión del ser ...», Ser y tiempo, op. cit., $\$ 43$, p. 233. Pero, ¿es esto último aceptable? En absoluto. Sosteniendo algo así se tergiversa y malentiende el nudo entre "ser» y "comprensión», es decir, el «darse del ser» en ella y a ella (donde «darse» equivale a «acontecer», al acontecer recurrente del ser como "principio», etc.).

27 Ahora bien, ¿̨cabe pensar, respecto a la "comprensión del ser» (y al ser que se da en una o a una comprensión) en unas «condiciones de posibilidad»? No, en modo alguno. Si en esto, pues, tenemos razón tiene que dejarse de preguntar por el «sentido del ser». 


\section{La analítica del Dasein y sus dos niveles}

Inicialmente - concluye Heidegger a través de una bien trabada argumentación- debe realizarse una "analítica del Dasein». En ésta se pregunta por el ser y el sentido del ente que soy yo o que nosotros somos con el objetivo de responder - desde lo encontrado aquí- a la pregunta central de la filosofía. En el $\$ 4$, por eso, se afirma: «... la analítica ontológica del Dasein en general constituye la ontología fundamental, de tal manera que el Dasein viene a ser el ente que en principio ha de ser previamente interrogado respecto de su ser» (Ser y tiempo, op. cit., p. 37) ${ }^{28}$.

Repararemos, ahora, en dos importantes distinciones — que pueden, tal vez, parecer «obvias», pero que encierran serios problemas-: entre «existenciarios» $\mathrm{y}$ «categorías», entre «lo existenciario» y «lo existencial».

La primera distinción — situada en la base de la diferencia entre la analítica del Dasein, como «ontología fundamental», y las «ontologías regionales»— se plantea en el $\$ 9$ : «Todas las explicaciones que surgen de la analítica del Dasein se alcanzan mirando hacia su estructura de existencia. Y como estos caracteres de ser del Dasein se determinan desde la existenciariedad, los llamamos existenciarios. Se los debe distinguir rigurosamente de las determinaciones de ser del ente que no tiene la forma de ser del Dasein, a las que damos el nombre de categorías ... Existenciarios y categorías son las dos posibilidades fundamentales de los caracteres de ser. El respectivo ente exige ser primariamente interrogado en forma cada vez diferente: como quién (existencia) o como qué (estar-ahí, en el más amplio sentido). Sobre la conexión de ambas modalidades de los caracteres de ser sólo se podrá tratar una vez aclarado el horizonte de la pregunta por el ser» (Ser y tiempo, op. cit., pp. 69-70). En principio, aunque sólo eso, los existenciarios (las características que nos definen) son "propiedades» de un ente que «carece de esencia» («La "esencia» del Dasein consiste en su existencia», op. cit., p. 67); las categorías, en cambio, son propiedades que definen a los entes de un modo de ser distinto al Dasein, a los entes que «tienen una esencia ${ }^{29}$. El Dasein,

28 «De ahí que la ontología fundamental, que está a la base de todas las otras ontologías [regionales], deba ser buscada en la analítica existenciaria del Dasein», Ser y tiempo, op. cit., $\$ 4$, p. 36.

${ }^{29}$ Cabe preguntarse aquí dos cosas estrechamente conectadas: ¿es cierto que la totalidad del ente se divide según clases de entes? ¿es verdad que a cada «clase de entes» le corresponde una y 
pues, es el ente que «es así» pero «puede ser de otra manera» (a él, pues, en exclusiva, le corresponde —o eso cree Heidegger — el régimen del «ser-posible») y los otros entes "son así y no pueden ser de otra manera» (son como son y punto final —están atados—, por lo tanto, al régimen del «ser-necesario»). En el próximo apartado volveremos a tocar este importante tema cuando expongamos la manera — muy problemática — en que, según Heidegger, se «relacionan» categorías y existenciarios.

La otra distinción sólo concierne al Dasein. Heidegger, en el texto del $\$ 9$ que acabamos de citar, sostiene que la analítica se ocupa del «Dasein en general». Pese a que el ente que soy o somos sólo «existe» — sin que le corresponda "esencia» alguna - cabe encontrar en él, como suyos, rasgos o características "comunes y permanentes». En el $\$ 5$, respecto al cometido de la analítica, se dice: «... no deberán sacarse a la luz estructuras cualesquiera o accidentales, sino estructuras esenciales, que se mantengan en todo modo de ser del Dasein fáctico como determinantes de su ser» (op. cit., p. 41). Nos topamos aquí, pues, ante la distinción entre lo ontológico-existenciario (los caracteres «necesarios y universales», «esenciales» de un ente inesencial) y lo óntico-existencial (los rasgos "particulares y contingentes»). Vamos a mencionar, respecto a este relevante y delicado asunto, tres cuestiones. En primer lugar no está nada claro - al menos para nosotroscómo Heidegger separa lo existenciario de lo existencial; por ejemplo en el $\$ 10$ del curso del semestre de verano de 1928 (GA 26) se afirma que el «cuerpo sexuado» es un rasgo contingente del Dasein, pero, ¿es esto así? ¿̨por qué? ${ }^{30}$. En segundo lugar los existenciarios recuerdan excesivamente a las viejas «facultades» (del «sujeto humano»), pero ¿es cierto que «tenemos» (Heidegger prefiere decir «somos») una serie de «facultades» idénticas y permanentes («innatas» está uno tentado a añadir) presentes en todo Dasein? ¿No será, más bien, lo que nos define un conjunto de "capacidades» adquiridas «en y por la praxis vital» (y que no tienen nada ni de «identidad» ni de «permanencia» —no son «universales antropológicos» ni algo de ese estilo-) ? En tercer lugar los existenciarios se entienden como «condiciones de posibilidad» de los comportamientos; ahora bien, no resulta nada

\footnotetext{
nada más que una esencia (postulando así un «universo eidético» único y definitivo como fundamento de las regiones categoriales)? A ambas cuestiones, por nuestra parte, le daríamos una respuesta negativa (siempre a partir de la "pregunta por el ser» como pregunta central de la filosofía).

${ }^{30}$ Véase el luminoso ensayo de Jacques Derrida, «Différence sexuelle, différence ontologique (Geschlecht I)», en Heidegger et la question, ed. Flammarion, 1990.
} 
claro cómo se pasa de los comportamientos a los existenciarios, baste un ejemplo de este esquema argumental: «me comporto sentimentalmente (siento temor o angustia) luego tiene que haber, en mí, un existenciario correspondiente que posibilite esta clase de comportamientos» (en el caso propuesto el llamado «Befindlichkeit», el «encontrarse»); pero, ¿convence este modo de proceder? En general, a nuestro juicio, el estatuto de los «existenciarios» —el tema mismo de la analítica del Dasein... es bastante confuso; ¿basta decir que son no "propiedades» que un ente tiene sino unos «modos de ser»? No lo creo. Además no está claro ni cómo se obtienen ni, tampoco porqué son los que se destacan en este tratado

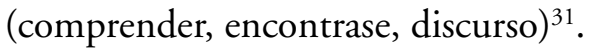

La analítica del Dasein toma como punto de partida — desde el que sacar a la luz la red de «existenciarios» que definen el ser del Dasein - el cotidiano seren-el-mundo (en el que el Dasein trata con plexos de útiles y con otros como él). Únicamente llamaremos la atención sobre una cierta incongruencia que percibimos aquí — una incongruencia que no es casual pues obedece a dificultades de fondo-—: inicialmente Heidegger sostiene que la "cotidianidad media» es «indiferente» (neutra, cabría decir) respecto a las dos grandes opciones del Dasein: el existir propio y auténtico y el impropio e inauténtico. Sin embargo según avanza la analítica se va identificando y equiparando cada vez más la «vida cotidiana» con la segunda opción de la alternativa. Heidegger no explica las razones de por qué, al final, niega lo que comenzó afirmando — es decir, nos deja a nosotros la tarea de entender por qué «se vio llevado a ello»"

La analítica del Dasein se desarrolla según dos estadios: en el primero se define el ser del Dasein, en el segundo se determina su sentido. Vayamos, pues, en primer lugar, con el asunto del «ser del Dasein» (del que se ocupa la primera sección del tratado de 1927). Con el fin de ir al meollo del asunto nos fijaremos, para empezar, en las dos partes del capítulo $\mathrm{V}$ tituladas: «La constitución existenciaria del ahí (Da)» y «El ser cotidiano del ahí (Da) y la caída del Dasein».

31 Por no haber criticado a fondo la idea de «facultades de un sujeto humano universal» Heidegger incurre, entendemos, en un "formalismo esencialista» (en la medida en que lo existenciario es pensado como «forma» y lo existencial como «contenido» — como lo que «llena» una forma previamente vacía-).

32 Algo parecido ocurre con la facticidad o arrojamiento (Geworfenheit): en principio nada parece tener que ver con la inautenticidad, sin embargo, poco a poco, se asimila a ésta (Ser y tiempo, $₫ 38)$, sin, de todos modos, llegar a identificarse del todo con ella. 
El término «ahí» $(\mathrm{Da})$ se refiere al núcleo del Dasein: a su «apertura» o «estado abierto» (Erschlossenheit). El Dasein es su apertura, es su ahi. En los $₫ 28$ y $\$ 69$ Heidegger conecta el fenómeno de la «apertura» y del «ahí» con el de la «luz» y la «claridad». Sería interesante detenerse aquí, principalmente para explicar con detalle que lo que aquí se sostiene es bien diferente de lo que — refiriéndose a este mismo tema - dirá Heidegger a partir de los años treinta (con la temática del «claro», de la «Lichtung», etc.). Nos centraremos, sin embargo, en otra cosa: en subrayar que la «apertura» del Dasein está surcada por tres existenciarios que se erigen en los principales precisamente por constituir su «estar abierto» ('prioritariamente para si? Cabe preguntar). Se trata de la "comprensión» (a través de la cual se destaca al Dasein como poder-ser, como proyecto de sus posibilidades), el encontrase (en el que se destapa la facticidad del Dasein, su estar «arrojado») y el discurso. Estos existenciarios — que posibilitan comportamientos del Dasein - se despliegan según dos modalidades: inauténtica (de la que se trata en el segunda parte del capítulo V) y auténtica (abordada como tal en la segunda sección de Ser y tiempo). Respecto a ellos —en tanto nuestro objetivo, más que «explicar» lo que Heidegger sostiene es apuntar lo que nos parece problemático o digno de discusión — señalaremos dos cosas. Por un lado Heidegger subraya que esos tres existenciarios son co-originarios; ahora bien, es evidente que entre ellos hay una asimetría que matiza esta afirmación: en efecto sólo la «comprensión» — desde el arranque del tratado— resulta puesta en conexión «directa» con el «ser» (nunca se habla aquí de un presunto «encontrase del ser» o un «discurso del ser»). Esta asimetría — que no desmiente la co-originariedad si por esta se entiende, nada más, que un existenciario no es derivable de otrose terminará convirtiendo en jerarquía: el existenciario primordial será, al fin y al cabo, la «comprensión». Por otro lado, y con esto formulamos únicamente una conjetura, cabe sospechar que la distinción entre existenciarios realizada por Heidegger no hace otra cosa que trasponer — por vía de una «ontologización»— la tripartición que encontramos en "psicologías descriptivas» como la de Brentano o la de Dilthey. Sería interesante averiguar si esto es así o no y, sobre todo, y esto es bastante más importante, entablar una discusión del asunto «desde la cosa misma» con el fin de aceptar o rechazar esa «tripartición» y, con ella, la posibilidad de su «trasposición» al marco de una «analítica del Dasein» ${ }^{33}$.

33 A nuestro juicio - y dicho sea sólo para no mantener continuamente un tono "negativo", de mero «rechazo sin propuesta»— sólo debe distinguirse dos vías en la «comprensión del ente»: el Sentir y el Decir. En ellos se insertan, como parte suya, nuestras «capacidades» (forjadas en y 
En la segunda parte del capítulo V se afirma (desmintiendo lo que se dijo al comienzo del libro) que el ser-en-el-mundo cotidiano implica la «caída» del Dasein, su inautenticidad, es decir, el «cierre» de su "apertura». ¿En qué consiste la "caída», pues? En que los tres existenciarios de la apertura del Dasein operan bajo modalidades «defectivas», «impropias; así en el $\$ 35$, $\$ 36$ y $\$ 37$ se estudian, respectivamente, el discurso, la comprensión y el encontrarse «inauténticos». Pero, ¿qué caracteriza, en general, la «caída» o el «decaer» del Dasein? El círculo de la cotidianidad se forja en el cruce entre dos existenciarios: ocuparse-de (Besrogen) y procurar-por (Fürsorge); ambos «fundan» o «condicionan» comportamientos de índole «intencional» —en la acepción fenomenológica del término: comportamientos dirigidos a un fenómeno que ante ellos se expone y revela- ¿Y qué ocurre en los «comportamientos intencionales»? Ante todo un estar «absorbidos en» o «volcados hacia» eso a lo que están referidos. Heidegger, por esto, sostiene que el Dasein cotidiano — caído, pues - es el que está atrapado en y atado por sus vínculos con el ente intramundano, unos vínculos que, a su entender (y cabe discutirlo — como haremos nosotros más adelante-) expropian al Dasein: lo despojan de lo más propio, de su más íntimo ser. No es casual, por ejemplo, que en el $\$ 41$ se sostenga que el ocuparse-de y el procurar-por son «restricciones» del «ser del Dasein»: el cuidado (Sorge). El ser-en-el-mundo cotidiano se caracteriza porque el Dasein «se descuida de sí mismo» y, a la vez, «cuida (prioritariamente) de aquello que comparece dentro del mundo». Tirando de este hilo Heidegger sostiene que el «cuidado» puja hacia su autenticidad (hacia la liberación del todo aquello que lo expropia de su ser) cuando se ejerce como un puro «cuidarse» (Selbstsorge); algo que, sin embargo, requiere «escaparse» o «sustraerse» al poderoso —y presuntamente «esclavizante»— influjo del mundo y lo mundano.

El cuidado, como ser del Dasein, es definido en el $\$ 41$ en los siguientes términos: «La totalidad existenciaria del todo estructural ontológico del Dasein debe concebirse, pues, formalmente, en la siguiente estructura: el ser del Dasein es un anticiparse-a-sí-estando-ya-en-(el mundo) en-medio-de (el ente que comparece dentro del mundo). Este ser da contenido a la significación del término cuidado (Sorge), que se emplea en un sentido puramente ontológico-existenciario» (Ser y

por la "praxis vital» — de manera que «el ojo es ojo viendo algo que se le ofrece en su visibilidad», etc.-). Desde este planteamiento, por otro lado, la «comprensión del ente» no es exactamente lo que Heidegger denomina un «existenciario» porque incluye (sin establecer entre ellos jerarquía alguna) lo que éste llama "categoría». 
tiempo, op. cit., p. 214). Se trata, por lo tanto, de una unidad con tres miembros; el primero se refiere a la comprensión (y, así, al proyecto), el segundo al encontrarse (y, por ello, al arrojamiento) y el tercero a la «caída», a la cerrazón respecto a sí mismo que define la inautenticidad o impropiedad (motivada según Heidegger, como hemos dicho, por los vínculos que el Dasein entabla y mantiene con lo intramundano). Precisamente la presencia de este tercer elemento en el seno del «cuidado» indica — como Heidegger explica en el $\$ 45$ - que, partiendo del ser del Dasein, debe aún alcanzarse un nivel más originario: el nivel del sentido (del ser) del Dasein. De llegar aquí — y de exponer lo que ahí se encuentra— se encarga la segunda sección de Ser y tiempo (a partir del $\$ 45$ hasta el final).

La puesta de relieve del sentido (del ser) del Dasein exige dejar de referirse al cotidiano ser-en-el-mundo del Dasein, es decir, requiere orientarse hacia el Dasein auténtico: el que remontando la caída ha ganado su modo propio y genuino de ser.

Cuando Heidegger orienta así su búsqueda, ¿qué encuentra? Principalmente tres comportamientos del Dasein que, por una parte, consiguen quebrar el seren-el-mundo cotidiano (sustrayéndole pues a su influjo) y, por otra parte, constituyen a la vez el punto álgido de sus respectivos existenciarios, su modalidad máxima y eminente. ¿De qué comportamientos se trata? De la angustia ( $\$ 40)$, la voz de la conciencia ( $\$ \$ 55-57)$, la resolución anticipante de la propia muerte $(\$ 60)$. Y, ¿a qué existenciarios remiten (de manera tal que marcan su punto álgido - a la vez que ejercen una suspensión de los vínculos con el ente intramundano en los que opera el vivir común y corriente-) ? Nada menos que a los tres existenciarios que integran la «apertura» o el «estar abierto» del Dasein: la angustia remite al «encontrarse», la voz de la conciencia al «discurso», la resolución anticipante a la «comprensión». Cabe preguntar ahora qué tienen en común esos tres señalados comportamientos del Dasein: por un lado son comportamientos puramente «autorreferenciales» (no, son, pues, comportamientos «intencionales» — como se ve en el análisis en el que Heidegger distingue el «temor» de la «angustia»—); por otro lado, al estar en ellos el Dasein referido o remitido sólo a sí mismo, nada más que a sí mismo (a sí mismo, en definitiva, como nada), puede decirse que los tres se presentan genuinamente como «experiencia de la nada», de tal manera que localizan en el Dasein un «poder nihilizador» ${ }^{34}$ (se pos-

34 En el importante $\$ 58$ de Ser y tiempo —en el que se anticipa la temática del artículo «De la esencia del fundamento»— se afirma, en esta línea, que el Dasein es un fundamento que, a su 
tula así, respecto al Dasein, una finitud y una negatividad para él irrebasables —además esa nihilidad suya puede ser irradiada o infundida a lo óntico en su totalidad, tal como Heidegger expone en el escrito «QQué es metafisica?»—).

La autenticidad del Dasein, pues, resulta definida por la conjunción y convergencia de tres comportamientos cuyo principal efecto es desatar los vínculos con todo lo intramundano, suspendiendo así la — presunta, pues esto puede discutirse- constricción del ser-en-el-mundo cotidiano. Gracias a ellos - como el «esclavo» de la caverna platónica- el Dasein resulta liberado de toda atadura, pudiendo mantener una relación consigo mismo absolutamente pura, sin interferencia o sin contaminación por parte de ningún agente exterior (una relación consigo mismo en la que el Dasein se vacía de todo «contenido" procedente de la exterioridad, en la que, por lo tanto, se alcanza en su propia «nada», en la nada que él mismo — como ente insustancial, carente de esencia- es).

A partir de la autenticidad del Dasein se puede llegar al «sentido» del ser del Dasein. Éste es —en la medida en que el «sentido» es algo «posibilitante»— respecto al ser del Dasein aquello que permite entender y explicar en su raíz el ser del Dasein en su modalidad auténtica. Según esto (Ser y tiempo, \$65) el sentido del ser del Dasein es la «temporalidad». Es ella, pues, la que posibilita el «cuidado» (en su estructura trimenbre) y, a la vez, los tres comportamientos en cuya convergencia se delimita el modo auténtico y propio de ser del Dasein. Un mínimo análisis de la noción de "temporalidad» destapada aquí por Heidegger requería un ensayo entero. Nos limitaremos - pues es suficiente de cara a nuestro propósito principal - a un breve apunte sobre el tema. Lo inicialmente característico de la temporalidad —como sentido del ser del Dasein— es: sus tres momentos (los éxtasis del futuro, presente, pasado) no se suceden; el tiempo se temporaliza, a la vez, en esos tres "éxtasis»; hay varias modalidades del tiempo según cuál sea el éxtasis que en cada caso rige esa temporalización. Desde nuestra perspectiva —en la que pretendemos señalar lo que nos parece más discutible o menos acertado de la propuesta heideggeriana- lo más importante se encuentra en el nexo entre la temporalidad del Dasein y el fenómeno, destacado por Kant en la Críti-

vez, no se fundamenta a sí mismo (esto diferencia la propuesta heideggeriana de las realizadas por las filosofías del sujeto más relevantes: en ellas el Sujeto humano es el fundamento del mundo porque se auto-fundamenta, porque reflexivamente ejerce una auto-posición como fundamento de la totalidad de lo óntico). 
ca de la razón pura, de la "autoafección» ${ }^{35}$. La idea de auto-afección es, en el seno esta vez de la temporalidad, lo mismo que antes vimos como auto-referencialidad de ciertos comportamientos (esos que, precisamente, definen la autenticidad del Dasein). Dicho con más precisión: según Heidegger lo que en último término posibilita esa autorreferencia son los éxtasis del tiempo, de un tiempo que se temporaliza de modo «auto-afectivo» (el «éxtasis» rector «afecta» — y, así, movilizaa los otros dos «éxtasis», etc.). Las lecturas más habituales de Heidegger, en este punto delicado, se quedan sólo, nos parece, con la mitad de la copla: sólo entienden la «extaticidad» de la temporalidad del Dasein como un «salir de sì del Dasein (algo que, ciertamente, encaja con la tesis con la que arranca la analítica del Dasein: «el Dasein es ser-en-el-mundo»). No decimos que esto sea falso: Heidegger así lo defiende. Decimos, nada más, que esto no es todo, que hay algo más que suele ser pasado por alto. Basta recordar, en primer lugar, que el ser-en-el-mundo remite siempre al Dasein impropio e inauténtico (a la «caída en el mundo» de la que antes hablamos). ¿Qué tiene que añadirse para que la exposición del tema sea completa? Que el sentido del ser sea la temporalidad — y que ésta sea entendida en su raíz como autoafección - implica concebir a cada éxtasis del tiempo originario del Dasein auténtico como un "volver a sí»: un movimiento centrípeto en el que y con el que el Dasein se «sustrae al mundo» (llegando a sí mismo como «nada»). Aquí se encuentra la razón de que el «futuro» —el éxtasis rector del tiempo originario, vinculado con la resolución anticipante de la propia muerte y, por ello, con la comprensión y el proyecto- sea definido como un «sich auf sich zukommen». Sólo a partir del «volver a sí mismo» (distinto en cada éxtasis del tiempo) ocurre el «salir de sí mismo»: un movimiento centrífugo en el que el Dasein "se mundaniza» — por decirlo así- y, por lo tanto, «cae cabe lo mundano» — siendo entonces atrapado o capturado por ello hasta que, tornándose auténtico, consiga anular su poderoso influjo- - En el «salir de sí», por otra parte, sucede algo que trataremos en el próximo apartado (algo que Heidegger aborda en el $\$ 69$ de Ser y tiempo - y que iba a constituir el contenido principal de la tercera sección, la que nunca llegó a ser publicada-).

¿Qué podemos concluir de nuestra exposición de las dos etapas de la analítica del Dasein? Sobre todo esto: el Dasein es definido en su autenticidad por la

35 Sobre este punto véanse los $₫ 11$ y $\$ 25$ del volumen veinticinco de las Obras Completas y el $\$ 34$ de Kant y el problema de la metafísica. En ellos se explica cómo y por qué Heidegger asume este hallazgo kantiano. 
pura referencia de sí mismo hacia sí mismo ${ }^{36}$. Por ello el ser del Dasein, el cuidado, es un cuidarse, la apertura o el estar abierto es un abrirse (el triple abrirse del Dasein por sí mismo) y, como raíz de todo ello, la temporalidad del Dasein es una temporalizarse. En cambio la inautenticidad del Dasein se define como la contaminación —efectuada por la exterioridad mundana — de esta pureza en la autorreferencialidad: la inautenticidad nos embarga cuando la referencia a nosotros mismos está interferida o perturbada por la relación con lo que no soy yo. Con esta descripción — de la que cabe discrepar (pues tal vez no se ajusta a los fenómenos) - Heidegger se acerca enormemente a unos planteamientos que, sin embargo, él mismo creía que estaba discutiendo: se aproxima a defender la originaria reflexividad del Sujeto tal como ha sido elevada a los altares por la filosofía moderna (a mi juicio exagerando su papel y sobrevalorando su poder). Hay, de todos modos, al menos una diferencia relevante que impide identificar al Dasein con el Sujeto moderno: el Sujeto, en y por su reflexión, pretende ponerse (autoerigirse) como el fundamento inconmovible del mundo; el Dasein, en cambio, en la medida en que en su "vuelta a sí mismo» no encuentra punto de reposo alguno — viéndose impelido a "salir de sí»— sólo es "fundamento» como «abismo», «sosteniéndose en la (o en su) nada» (es lo que, en la estela del $\$ 58$ de Ser y tiempo, se afirma en "¿Qué es metafisica?" y en «De la esencia del fundamento»). El Dasein es, en el fondo, finito: está atravesado por una negatividad de la que no puede nunca desprenderse.

Antes de continuar. ¿Qué decir de lo que, en conjunto, hemos expuesto hasta aquí? Más allá de que se encuentren algunos hallazgos de primer orden — que no deberían caer en saco roto- el conjunto de la trama no nos parece sostenible. Ni hay, creemos, comportamientos puramente autorreferenciales (es decir, comportamientos no intencionales), ni la «autenticidad» requiere un sustraerse al ser-en-el-mundo (sí, desde luego, una «suspensión de lo vigente» — Gadamer diría con razón: la quiebra de un "prejuicio del comprender»-, pero esto no implica ni necesita de ninguna ilusoria "vuelta a sí mismo»); tampoco la temporalidad (en su múltiple temporalizarse) es en su núcleo «autoafección», ni, en definitiva, nos es inherente el doble movimiento de «volver a sí» y «salir de sí». Son éstas, nos parece, descripciones erróneas de fenómenos verdaderos. Ahora bien, si no se presenta una alternativa coherente a las descripciones del primer

36 Algo que encaja bastante bien con el antropocentrismo - y el antropomorfismo que desde él se propaga- propio de la era moderna del mundo. 
Heidegger lo que estamos diciendo será, hasta entonces, poco más, que una mera y vaga conjetura sin ningún alcance probatorio. A llevar a cabo esa tarea lo mejor que sepamos, pues, quedamos en adelante comprometidos.

\section{La sección faltante}

Según el plan expuesto en el $\$ 8$ del tratado de 1927 la primera parte incluía, como colofón, una tercera sección que nunca fue, finalmente, publicada. Heidegger intentó redactarla pero no le fue posible. Poco a poco cayó en la cuenta de que algo no iba bien en el planteamiento mismo de su primer programa filosófico. El «medio» - la analítica del Dasein — no conducía al fin propuesto — relanzar la pregunta por el ser-.

Nos ceñiremos, en este apartado, a ofrecer una idea sobre qué iba a contener esa sección. Acudiremos, para ello, a los $\$ \$ 5$ y 69 de Ser y tiempo y, también, al importante curso, impartido en el semestre de verano de 1927, Los problemas fundamentales de la fenomenología.

En primera instancia la analítica del Dasein —y en tanto no se adujeran pruebas suplementarias - era, sólo, una indagación referida al ser y al sentido de un ente. Es cierto, si hacemos caso a los $\$ \$ 2$ y 4 de Ser y tiempo, que se trata de un «ente señalado», marcado precisamente por la "comprensión del ser». La pretensión era, pues, ofrecer en y desde la analítica del Dasein una «ontología fundamental» es decir, una respuesta a la pregunta por el «sentido del ser en general» que permita, a continuación, desarrollar las pertinentes y oportunas «ontologías regionales». Para llegar aquí debe demostrarse que el sentido del ser el Dasein es idéntico al sentido del ser en general ${ }^{37}$. Y de hacerlo $-\mathrm{o}$, al menos de intentar-

37 Felipe Martínez Marzoa explica así el asunto: «¿Qué debería, pues, manifestarse en la tercera sección de la primer parte? Las reiteradas, aunque poco explícitas, declaraciones de intenciones que se encuentran en la parte redactada de la obra (y en otras partes de la obra total de Heidegger) nos permiten indicar lo siguiente: ... la comprensión del ser del Dasein habrá de manifestarse como comprensión del ser en general; por lo tanto, aquello que se habrá revelado como el horizonte o fondo a partir del cual, sobre o hacia el cual es posible la comprensión del ser del Dasein, eso mismo habrá de revelarse también como el horizonte o fondo a partir del cual, sobre y hacia el cual es posible la comprensión del ser. La Existenz no es el ser; el ser del Dasein no es el ser en general; pero el sentido del ser del Dasein es el sentido del ser en general», El sentido y lo no-pensado, op. cit., p. 10. 
lo - se ocupaba una parte de la indagación —esencial, como se ve — titulada coherentemente «tiempo y ser» (una vez que se ha concluido, en la segunda sección, que la "temporalidad» es el sentido del ser del Dasein). ¿Será, en definitiva, «el tiempo» el sentido del ser en general? ¿Será él, entonces, la clave con la que elaborar las distintas «ontologías regionales»? A éstas y a otras cuestiones centrales tenía que dar respuesta la tercera sección.

La tesis principal de Heidegger es la siguiente: en el «salir de sí» de los éxtasis de la temporalidad del Dasein (entraña de sus existenciarios) éstos desembocan en unos horizontes que constituyen el término (la línea de reposo) del doble movimiento del temporalizarse del Dasein. Heidegger, y es este un aspecto clave en su enfoque, propone entender el «horizonte» como un "esquema» en su acepción kantiana ${ }^{38}$ : los esquemas horizontales se erigen así en el núcleo de las «categorías», de las «regiones categoriales». A partir de aquí ¿qué pretendía o qué se proponía llevar a cabo Heidegger? Sacar adelante las ontologías regionales mostrando, sistemáticamente, cómo los éxtasis de la temporalidad (Zeitlichkeit) del Dasein rinden o producen esquemas horizontales (la «Temporalität des Seins») que hacen posible la comprensión del ente (permitiendo que los comportamientos intencionales del Dasein descubran los entes de una región determinada) ${ }^{39}$.

Con esto, por otra parte, se da respuesta a un asunto central que había quedado pendiente en el $\$ 9$ cuando se decía: «Exitenciarios y categorías son las dos posibilidades fundamentales de los caracteres del ser ... Sobre la conexión de ambas modalidades de los caracteres del ser sólo se podrá tratar una vez aclarado el horizonte de la pregunta por el ser». Pues bien, a partir de la tesis anterior (los esquemas horizontales son producidos por los éxtasis del tiempo del Dasein, etc.), se postula la siguiente conexión entre estos «caracteres de ser»: las categorías dependen de los existenciarios, tal y como, y porque, los esquemas horizontales dependen de los éxtasis del tiempo del Dasein. En el escrito de 1928 «De la esencia del fundamento», siguiendo en esta misma estela, se le atribuye al Dasein (como primer vector del triple fundar que él ejerce) la "proyección del mundo» o lo que, en otros textos de este periodo, se llama «proyecto del ser». Cuando se

38 Sobre esto véanse los $\$ \$ 31-35$ del volumen veintiuno de las Obras Completas, el $\$ 26$ de volumen veinticinco y los $\$ \$ 19-23$ de Kant y el problema de la metafísica.

39 La «Temporalität des Seins» es, pues, lo horizontal (lo esquemático) del tiempo extático del Dasein. 
proyecta (cuando proyecta posibilidades de sí mismo) el Dasein proyecta el mundo como ese horizonte (o esquema horizontal) a partir del cual comparecen los entes intramundanos en distintas regiones (configuradas a través de sus correspondientes categorías).

Era así como la prometida —al inicio del programa filosófico- recuperación de la ontología reiteraba una tesis procedente del idealismo filosófico: las condiciones de posibilidad de la comprensión del ser del ente en general residen en el Dasein, es más: en última instancia esas condiciones de posibilidad son suyas. El Dasein se erige así, pues, como un «Sujeto del mundo» pretendiendo poseer, en definitiva, una prioridad respecto al «ser como tal» (concebido como el «efecto» de un proyectarse a sí mismo por sí mismo). Ahora bien, ¿¿Es esto palmario y evidente? ¿Es una conclusión inevitable? ¿Es el «idealismo» (la fundamentación del mundo en el Sujeto humano) la mejor posibilidad de la filosofía? ¿No será la pregunta por el ser «algo más» que la pregunta por el hombre?

\section{El último parágrafo}

El parágrafo final de Ser y tiempo, titulado «La analítica temporal-existenciaria del Dasein y la pregunta ontológico-fundamental por el sentido del ser en general», es interesante por varios motivos. Por ejemplo porque manifiesta sin subterfugios dudas — que entonces le parecían a Heidegger provisionales, abordables en el marco de su primer programa filosófico (pero que se revelaron, finalmente, insolubles, definitivas) — sobre pilares básicos de su planteamiento y propuesta. Lo recorreremos, por esto, paso a paso.

Comienza Heidegger resaltando el resultado más granado - y aparentemente prometedor- de su investigación: la temporalidad es el sentido del ser del Dasein, del ente que soy yo o que somos nosotros (así, por ejemplo, a cada unos de los tres elementos del cuidado le corresponde uno de los tres éxtasis del tiempo —o, más en general, como exponen los $\$ \$ 67-71$, todo existenciario tiene una entraña temporal-). Sin embargo, nos recuerda a continuación, con esto no termina la tarea afrontada. La analítica del Dasein es un punto de partida, no el punto de llegada, es un «medio», no el fin último: «... la exhibición de la constitución del ser del Dasein sigue siendo tan sólo un camino. La meta es la elaboración de la pregunta por el ser en general. La analítica temática de la existencia 
necesita, por su parte, de la luz que viene de la previa aclaración de la idea del ser en general» (Ser y tiempo, op. cit., p. 449).

Inmediatamente se plantea en el texto un dilema sobre cuya relevancia nunca se insistirá lo suficiente: ¿la cimentación de la ontología debe ser «óntica» o tiene que ser «ontológica»? Leemos: "Ciertamente tampoco esta tesis debe tomarse como un dogma, sino como una formulación del problema fundamental, que sigue estando "velado»: ¿puede la ontología fundarse ontológicamente, o requiere también un fundamento óntico, y cuál es el ente que debe asumir la función fundante?» (op. cit., p. 450). La respuesta de Heidegger hasta aquí ha sido inequívoca: debe partirse - por las razones que ya hemos expuesto- de un ente, el Dasein ${ }^{40}$. Pero lo interesante es que ya aquí — por más que en primera instancia no la tome en consideración- deja abierta otra opción: precisamente la que intentará seguir a partir de los años treinta.

Hasta este momento la analítica del Dasein ha empleado como referencia constante la diferencia entre «dos modos de ser»: el Dasein y el ente que no tiene su modo de ser (algo en lo que se basa la distinción entre «existenciarios» $\mathrm{y}$ «categorías»). Pues bien, ahora nos señala que esa «diferencia» no constituye algo en lo que se pueda permanecer sin más: «La distinción tan manifiestamente obvia entre el ser del Dasein existente y el ser de los entes que no son el Dasein (el estarahí, por ejemplo), es tan sólo el punto de partida de la problemática ontológica, y no algo en lo que la filosofía pudiera hallar su reposo» (op. cit., p. 450). Reposar en un dualismo básico era lo que, en el fondo, por ejemplo, hacía Husserl cuando (Ideas relativas a una fenomenología pura y una filosofía fenomenológica, $\$ 42)$ trazaba la diferencia entre el «ser como conciencia» y el «ser como realidad» — sosteniendo, a continuación una tesis idealista: «lo real es lo que resulta constituido por la conciencia»- Por eso Heidegger, distanciándose de su maestro,

40 «Sólo hay ser si hay comprensión de ser, esto es, si existe el Dasein. Por consiguiente, este ente exige, en la problemática de la ontología, una preeminencia especial, que se pone de relieve en cada discusión de los problemas ontológicos fundamentales, sobre todo en la cuestión fundamental acerca del sentido del ser en general. La elaboración y la consideración de estas cuestiones exigen una analítica general del Dasein. La ontología tiene como disciplina fundamental la analítica del Dasein. En ello se basa así mismo el hecho de que la ontología no pueda fundamentarse de forma puramente ontológica. Su posibilidad misma remite a un ente, esto es, a lo óntico: al Dasein. La ontología tiene un fundamento óntico», Los problemas fundamentales de la fenomenología, op. cit., p. 45. 
añade al respecto lo siguiente: «¿Basta siquiera la "distinción» de "conciencia» y «cosa» para un desarrollo originario de la problemática ontológica? ¿Están a nuestro alcance las respuestas a estas preguntas? ¿Y es posible siquiera buscar la respuesta, mientras no se plantee y aclare la pregunta por el sentido del ser en general?» (op. cit., p. 450).

Tras poner el punto de mira en dos de las principales líneas de flotación de su programa filosófico se pregunta sin tapujos si éste —el de apostarlo todo a la carta de una «analítica del Dasein» como «ontología fundamental», etc.— es el camino correcto o si se trata de un camino, tal vez, errado. Algo que, desde luego, sólo se dirime en la medida en que se recorra ese camino: sólo así se verá si conduce propiamente a la meta o si nos desvía de ella. Si así fuese — si concluyésemos que ocurre esto último- habría que volver sobre los pasos dados e indagar cuáles de ellos arruinaron el intento.

Por último este parágrafo explica a dónde ha llegado la investigación, un punto de llegada provisional que más que una respuesta suscita una cascada de preguntas: «Eso que llamamos «ser» está abierto en la comprensión del ser que, en cuanto comprender, es constitutiva del Dasein existente. La apertura — previa, aunque no conceptual- del ser hace posible que el Dasein, en cuanto existe como un ser-en-el-mundo, pueda habérselas con el ente, tanto con el que comparece dentro del mundo como consigo mismo en cuanto existente. ¿Cómo es posible propiamente para un Dasein la comprensión abriente del ser? ¿Podremos responder a esta pregunta retornando a la constitución originaria del ser del Dasein comprensor del ser? La constitución ontológico-existenciaria de la totalidad del Dasein se funda en la temporalidad. Por consiguiente, el proyecto extático del ser en general deberá ser posibilitado por un modo originario de temporalización de la temporalidad extática misma. ¿Cómo se debe interpretar este modo de temporalización de la temporalidad? ¿Hay algún camino que lleve desde el tiempo originario hacia el sentido del ser? ¿Se revela el tiempo mismo como el horizonte del ser?» (op. cit., pp. 450-451). De nuevo aquí, otra vez, Heidegger subraya que el sentido del ser en general es — debería ser, parece ser- la "condición de posibilidad» de la comprensión del $\operatorname{ser}^{41}$. Es decir: la temporalidad del

41 Así lo explica en el curso del semestre de verano de 1927: «¿Por qué vía cabe penetrar en el sentido del ser en general? Si — como es habitual— se es dogmáticamente de la opinión de que el ser es el concepto más general y más simple, ¿̨no es la cuestión por el sentido del ser y la tarea de 
Dasein es — parece ser, debería ser- lo que posibilita la comprensión del ser «en general». Pero ya, como se ve, el propio Heidegger vacila, no lo toma como algo evidente o como un resultado firme y seguro: ¿es así? se pregunta el autor (y nos pregunta a nosotros, los lectores de su indagación). Dejándonos en ascuas, en vilo, nos remite —en este punto y seguido del tratado que se convirtió, a pesar suyo, en el punto y final- a la tercera sección. La que no pudo ser redactada - y de la que tratamos en el apartado anterior-.

\section{Objeciones y sugerencias}

\subsection{Objeciones}

Hemos ido salpicando, en el recorrido hecho hasta aquí, un buen número de dudas: las que nos suscitaban a cada paso las tesis y los argumentos de Heidegger. Con el fin de profundizar en esto enfocaremos así el asunto: señalaremos, con brevedad, los más prometedores y brillantes hallazgos propios del primer programa filosófico de Heidegger para mostrar, a la vez, por qué nos parece que el marco teórico en el que fueron implantados les impidió, en última instancia, ofrecer sus mejores frutos (con el fin de que nos brinden sus mejores posibilidades la constatación anterior — si fuese cierta y exacta — obliga a poner en tela de juicio una serie de supuestos de los que entonces Heidegger no fue capaz de deshacerse).

En primer lugar el ser «se da» en una comprensión (¿Como qué? como lo que determina al ente en cuanto ente). Estamos aquí ante un hallazgo de primera magnitud. Ahora bien, este «darse del ser en la comprensión» fue malentendido

una aclaración de este concepto una pseudocuestión? ¿¿A partir de qué puede ser determinado y en qué se puede analizar? Algo así como el ser se nos da en la comprensión del ser; en la comprensión del ser que subyace en todo comportamiento respecto del ente. Los comportamientos respecto del ente pertenecen, por su parte, a un determinado ente, aquel que somos mismos, el Dasein humano. A este pertenece la comprensión del ser que posibilita antes que nada todo comportarse respecto del ente. La comprensión del ser tiene ella misma el modo de ser del Dasein humano. Cuanto más originaria y adecuadamente determinemos este ente respecto de la estructura de su ser, es decir, lo determinemos ontológicamente, con mayor seguridad estaremos en disposición de captar, en su estructura, la comprensión del ser que pertenece al Dasein y con mayor claridad se podrá entonces plantear la cuestión: ¿qué es lo que hace posible esta comprensión del ser en general? ¿a partir de qué, es decir, a partir de que horizonte previamente dado comprendemos algo así como el ser?», Los problemas fundamentales de la fenomenología, op. cit., p. 41. 
cuando —en lugar de entenderlo como un inagotable acontecer, una eclosión que adviene una y otra vez- se lo concibió como el término de un "proyecto» efectuado por el Dasein. Afirmar que «ser» —en vez del acto en el que y por el que aparece lo que aparece y se sustrae lo que se sustrae - es lo proyectado por el Dasein auténtico a partir del tiempo originario (desde su temporalizarse — su abrirse, trascenderse-) es sostener, en definitiva, una tesis idealista que puede ser refutada «a partir de la cosa misma» $»^{42}$. No es casual que en el no 242 de Beiträge zur Philosophie (von Ereignis) Heidegger afirme que en su primera propuesta filosófica el «ser» resultaba indebidamente «objetivado», es decir, tratado como algo que el Dasein pone desde sí mismo ante sí mismo (y lo pone, precisamente, como la vertiente horizontal y esquemática del tiempo extático del Dasein).

Otro logro enorme consiste en situar en primer plano la tesis de que el ser no es un ente, es decir, de resaltar la diferencia del ser respecto a todo lo óntico. ¿Cómo desvirtuó este crucial hallazgo? En la medida en que pretendía «fundamentar ónticamente la ontología» se veía obligado, en última instancia, a sostener que la diferencia entre el ser y los entes se lleva a cabo — se produce, se deriva- a partir de una distinción entre entes: la del Dasein y el ente distinto del Dasein. Sin embargo la «diferencia ontológica» es algo originario, nunca un producto o un resultado de una diferencia "más básica» ${ }^{43}$.

El existir concebido como ser-en-el-mundo es otro importante punto de anclaje del que la filosofía no debe prescindir. Gracias a él podemos, por un lado, discutir en su raíz la escisión sujeto/objeto (que surge de romper indebidamente lo que está unido); por otro lado, permite fundar adecuadamente la «intencionalidad» de los comportamientos de la vida fáctica (su estar siempre dirigidos hacia algo fenoménico que comparece — siendo esto o aquello- en las situa-

42 El Idealismo filosófico reposa, principalmente, en una errónea descripción de lo que somos nosotros (una descripción en la que se nos sitúa como fundamento del mundo, como «sujeto» - lo que subyace a todo-). En vez de afirmar que soy una parte (un elemento o un ingrediente) de las "condiciones de posibilidad» de la comprensión óntica o fenoménica equivocadamente nos concibe como el soporte único de ellas (como su «dueño y posesor»), algo que implica, de entrada, tergiversar el «a priori de correlación» (el cual atraviesa y sostiene — junto al «círculo de la comprensión»- toda comparecencia de algo como algo). Un a priori puesto de relieve con perspicacia por lo más granado de la tradición fenomenológica (por ejemplo Maurice Merleau-Ponty).

43 Véase la lucida exposición de este problema por Ramón Rodríguez en las páginas 220-221 La transformación hermenéutica de la fenomenología, ed. Tecnos, 1997. 
ciones experienciales en las que participamos). ¿Cómo fue malogrado? Por la vía de identificar el ser-en-el-mundo (y el consiguiente estar ya siempre cabe el ente intramundano) con la "caída», con el existir impropio e inauténtico. A partir de esta identificación Heidegger tuvo que definir, inevitablemente, la autenticidad del Dasein como el logro (en comportamientos puramente autorreferenciales - la angustia, etc.-) un desbaratamiento del ser-en-el-mundo en el que conseguía sustraerse a su poder de atracción y seducción (un poder contrarrestado por el poder nihilizador desplegado gracias a los comportamientos autorreferenciales tematizados en la segunda sección de Ser y tiempo). Según este planteamiento - que debe ser enjuiciado, desde luego, desde los fenómenos mismos- el Dasein «sale de sí» (es en el mundo — cayendo en él—) desde un más originario y previo «volver a sí» (en esos comportamientos autorreferenciales que definen su autenticidad y que resultan posibilitados por la temporalidad extática en su vertiente centrípeta). No es casual que en los escritos inmediatamente posteriores a Ser y tiempo Heidegger intentase fundar la «intencionalidad» en lo que denomina la «trascendencia del Dasein». Ahora bien, a nuestro juicio, por este camino se malogra el hallazgo que estamos destacando. Y se desvirtúa, otra vez, desembocando en una tesis idealista que impide reconocer lo que debería ser reconocido: el ser-en-el-mundo como campo fenoménico básico en donde comparecen los entes siendo esto o siendo aquello — siempre en el seno de los ámbitos del saber que roturan y articulan ese «claro abierto y despejado»—.

Con vigor argumenta Heidegger que la verdad no es solamente «adecuación» $\mathrm{y}$ «conformidad» sino también, posibilitando esta dimensión de la verdad, «descubrimiento y apertura» (Ser y tiempo, \$44). ¿Por qué arruina este prometedor planteamiento? Por un lado porque (traicionando la correlación a priori propia de la fenomenalidad — del darse de algo como algo, de ofrecerse en sentido en su verdad-) atribuye unilateralmente al Dasein el papel de descubrir al ente (como si éste último no pusiese absolutamente nada de su parte) ${ }^{44}$; por otro lado porque la "apertura» se concibe — en coherencia, eso sí, con la primacía de lo

44 Es significativo, al respecto, dónde sitúa Heidegger el ser-posible (las posibilidades, en definitiva): en vez de localizarlas en medio del ser-en-el-mundo (entreverando "existenciarios" y "categorías» - por expresarnos según el vocabulario de Heidegger-) se las asigna unilateralmente al Dasein (como si las "posibilidades» nada tuviesen que ver con el ente distinto del Dasein). Con razón, nos parece, Félix Duque, en El mundo por de dentro, ed. Serbal, 1995, p. 32, afirma que las «determinaciones» (el darse del sentido en su verdad) ocurren en el seno de una "transacción» entre «nuestras potencialidades y las posibilidades de las cosas». 
autorreferencial que Heidegger cree localizar en el Dasein — como un abrirse del Dasein efectuado desde sí mismo y por sí mismo, un abrirse en el que (en detrimento de la «verdad del ser» — que Heidegger tematiza a partir de los año treinta-) se alcanza la «verdad de la existencia» (Ser y tiempo, \$60). Es así como, dicho sucintamente, este hallazgo, nos parece, se desfigura casi por completo ${ }^{45}$.

Respecto al espacio y el tiempo destacaremos, como hallazgos suyos, al menos esto: Heidegger muestra que ni el primero es sólo «extensión» (por eso saca a la luz el «espacio pragmático» del vivir cotidiano) ni el segundo es sólo «sucesión»; en general ni espacio ni tiempo son únicamente magnitudes homogéneas e ilimitadas. Además reconoce en ellos modos de ser distintos: localiza una multiplicidad de maneras de ser tiempo el tiempo o espacio el espacio. Más aún: remite el tiempo a una (su) temporalización y el espacio a una (su) espacialización. ¿¿Cómo y por qué malogró estos meritorios y prometedores logros (que abren un basto campo de posibles indagaciones)? Poniendo unilateralmente en el haber del Dasein esa temporalización y esa espacialización: es el Dasein quien —según Heidegger- espacializa y quien temporaliza. De nuevo aquí se le atribuye al Dasein —se nos asigna a nosotros mismos - un papel protagonista que, a nuestro juicio, y por más que alimente nuestra inclinación narcisista, no nos corresponde: ninguna descripción imparcial de los fenómenos muestra nada parecido a lo que Heidegger sostiene.

Recapitulando diremos que, siempre a nuestro entender, no cabe, en modo alguno, preguntar por el sentido del ser en general, es decir, por las condiciones de posibilidad de la comprensión del ser; tampoco debe, por otro lado, creerse que se las va a encontrar a través de una analítica del Dasein. ¿¿Por qué? Principalmente porque ni hay esas condiciones de posibilidad ni, por lo tanto, residen en el Dasein como suyas. Si se pregunta ¿̇a partir de qué «ser» resulta comprendido? La única respuesta posible es: a partir de nada, pues, y es lo que en el fondo importa destacar, la comprensión del ser no puede ser condicionada (en su mismo planteamiento la pregunta por el sentido del ser lleva implícita la subordinación del «ser» al Dasein —el cual se cree en posesión de las condiciones a priori de su comprensibilidad). Si en esto tuviésemos razón — lo que está, desde luego, por verse- ocurrirían varias cosas. Por ejemplo no habría ningún «más allá del ser»: por creerlo Heideg-

45 La proximidad a la moderna filosofía del Sujeto de la tematización heideggeriana de la «apertura del Dasein» ha sido destacada por Ramón Rodríguez en la p. 121 de su Heidegger y la crisis de la época moderna, ed. Síntesis, 2006. 
ger atribuyó al «sentido» el papel de contener unas condiciones de posibilidad inexistentes. Lo primero y primario es el «ser»: él acontece — cada vez- como principio; es decir: es menester defender la prioridad del ser respecto al comprender y, así, respecto al Dasein. Tampoco, por otra parte, el tiempo puede jugar un papel tan relevante en el seno de los problemas ontológicos como el que el primer Heidegger le asigna. Menos aún las "categorías» (de las «regiones ónticas») dependen unilateralmente de los existenciarios del Dasein: no son algo «constituido» — «proyectado» como prefiere decir Heidegger— por el Dasein.

En definitiva nos parece que la pretensión de fundar ónticamente la ontología lleva a pensar el ser del ente sólo desde o hacia el ente. ¿Por qué el «segundo Heidegger» dejó de sostener semejante planteamiento? Porque así es imposible respetar y asumir en su plenitud la diferencia del ser con el ente. Se dibuja así el reto de pensar el ser (del ente) sin el ente (sin tomar el ente aparecido como modelo de todo aparecer posible, es decir, de todo aparecer necesario). La pregunta por el ser, pues, no sólo pregunta por el «ser del ente» sino también, más profundamente, por el «ser como ser», reconociendo entonces la complejidad de la «comprensión del ser» - y tratando de desentrañarla con una teoría filosófica que haga justicia a esa complejidad-. ¿Cuál es, según lo expuesto, la gran lección de Ser y tiempo (una lección implícita en su inacabamiento)? Tal vez ésta: plantear la pregunta por el ser exige que el Dasein (nosotros mismos) abdique de su pretensión narcisista de erigirse en el fundamento del mundo y del ser. Algo que implica dejar de plantear la pregunta por el sentido del ser. Entonces, ¿qué hacer? Diremos algo al respecto, para terminar, en la siguiente sección.

\subsection{Sugerencias}

Cerramos este ensayo - excesivamente volcado hacia un «no es esto» (cuando lo único importante es poder sostener con argumentos apoyados en los fenómenos «es esto») - con unas pocas sugerencias sobre algunas posibles correcciones que ayuden — tal vez, en el mejor de los casos- a evitar las aporías que decretaron la inconclusión del primer programa filosófico de Heidegger ${ }^{46}$.

46 En nuestro artículo «Mordiendo la fruta prohibida (notas para una reforma de la hermenéutica)» —en www.sebal.pntic.mec.es/AParteRei (n. ${ }^{\circ}$ 53, septiembre 2007)— puede verse con más precisión qué es lo que planteamos. 
En efecto la filosofía tiene por tarea explicitar, sacar a la luz, las «condiciones de posibilidad». Pero éstas sólo operan — sean las que sean- respecto a la comprensión óntica o fenoménica. La comprensión del ente o del fenómeno (del sentido en su verdad) está múltiplemente condicionada, o dicho de otro modo: toda experiencia de los fenómenos (sea en el ámbito del saber que sea —en las ciencias o en las artes, por ejemplo-) es "mediata», está sostenida y atravesada por una compleja red de mediaciones ${ }^{47}$. Resulta falso, pues, el gran mito de la metafísica de la Presencia: el mito de una experiencia inmediata y directa — en la que algo se da y ofrece del todo y definitivamente en un saber absoluto ${ }^{48}$ - ¿ ¿Dónde buscar, por otra parte, las condiciones de posibilidad de la comprensión óntica o fenoménica? En la comprensión del ser. Una comprensión del ser que es, a su vez, triple, es decir, el ser se da o acontece (una y otra vez, recurrentemente) en la comprensión diversificándose en una triplicidad: comprensión del ente en su ser, del ser del ente, del ser como ser. Si esto fuese así la investigación filosófica tendría que recorrer una por una estas tres direcciones. Además, y como parte de este planteamiento, la analítica del Dasein sería sustituida en su papel de hilo conductor por una teoría de los saberes ónticos o fenoménicos, es decir, por una descripción sistemática de qué ocurre —en el nivel de las condiciones de posibilidad- al comprender algo como algo (al comprender un sentido en su verdad).

Las posibilidades, por otro lado, no son — como se dice en Ser y tiempoposibilidades del Dasein. ¿Entonces? Explicándolo en los términos del tratado de 1927: las posibilidades — a partir de las cuales en los distintos ámbitos del saber los entes resultan descubiertos- se configuran en medio del ser-en-el-mundo, conciernen pues, a la vez, enlazándolos, a "existenciarios» y «categorías» (y prohibiendo, entonces, la tesis de que las segundas dependen de los primeros).

La más alta posibilidad del existir no es la propia muerte, como se sostiene en Ser y tiempo. Prolongando una idea que Heidegger roza en el $\$ 48$ diríamos: en lo que nosotros respecta la más alta posibilidad se cifra en participar en el juego del saber allí donde y cuando en éste fraguan y se plasman obras excelentes, obras maduras, obras «clásicas» (en las ciencias o en las artes, por ejemplo).

47 Así cuando Gadamer, por ejemplo, nos dice que toda comprensión de algo está guiada y dirigida por un "prejuicio» está poniendo de relieve una de esas «mediaciones».

48 La postulación platónica de un «universo eidético» es una poderosa modulación de este «mito», de esta tenaz «ilusión». 
Por último, si el término «Dasein» nos corresponde en algún modo —y es más apropiado que otros para definirnos - es no porque yo soy (o nosotros somos) quien posee las condiciones de posibilidad de la comprensión del ser ni tampoco — como a veces dicen algunos lectores del «segundo Heidegger»— porque soy (o somos) «el ahí del ser». Ese término sólo nos puede ser asignado porque soy uno de los elementos del «ahí» (Da) del ser: un ingrediente del "claro», del orbe abierto en el que, a la vez, acontece el ser (como principio, fuente de posibilidades) y en el que el ente se manifiesta siendo esto o siendo aquello. Dicho de otro modo: soy una parte de las condiciones de posibilidad de la comprensión. No soy pues, sólo, un ente del mundo o un ente en el mundo sino una «coordenada» suya (un «límite del mundo», por decirlo con Eugenio Trías), una "coordenada» necesaria, pero una entre otras más (Heidegger suele referirse a cuatro: cielo y tierra, dioses y mortales, a cuya convergencia y divergencia llama "Geviert»). Se apuntan aquí, en todo caso, cuestiones que, nos parece, merece la pena perseguir.

\section{Bibliografía}

BECH, J. M. (2001), De Husserl a Heidegger, ed. Universidad de Barcelona.

Blattner, W. D. (1999), Heidegger's Temporal Idealism, ed. Cambridge Univ. Press.

BeCKer, R. (2002), Sinn und Zeitlichkeit, Königshausen und Neumann.

DaSTUR, F. (1998), Heidegger et la question du temps, ed. PUF.

DerRIDA, J. (1987), Heidegger et la question, ed. Flammarion.

GreisCH, J. (1994), Ontologie et temporalité, ed. PUF.

HeInZ, M. (1982), Zeitlichkeit und Temporalität, ed. Rodopi.

Herrmann, F. W. von (1997), La segunda mitad de «Ser y tiempo», ed. Trotta.

Martínez MarzoA, F. (1985), El sentido y lo no-pensado, ed. Univ. de Murcia.

- (1999), Heidegger y su tiempo, ed. Akal.

PeÑalVer, P. (1989), Del espiritu al tiempo, ed. Anthropos.

RodríGUEz GARCía, R. (1997), La transformación hermenéutica de la fenomenología, ed. Tecnos. 
- (2006), Heidegger y la crisis de la época moderna, ed. Síntesis.

Segura, C. (2002), Hermenéutica de la vida humana, ed. Trotta.

- (2007), Heidegger y la metafísica, ed. Publidisa.

Recibido: 6/09/2010

Aceptado: 19/10/2010 